Problematic AIDS affects not only the physical health of individuals but also their family and community identity. Indeed, the stigma and discrimination surrounding the disease are equally destructive as the disease. This stigma is so strong in groups that have been affected by armed conflict, such as ex-combatants. To improve the status of veterans in their host communities in the reduction of risk behaviours facilitating the transmission of HIV/AIDS, FACOSASE form 360 PEEXC wished to fight against this scourge.

Objective To show PEEXC on how to improve the strategy of reducing risk behaviours favouring the transmission of HIV/AIDS.

IVMethod: To implement this training strategy as PEEXC reduction of risk behaviours facilitating the transmission of HIV/AIDS, we first conducted a raid on land in order to identify PEEXC who will participate in the training.

Results At the end of the training, there is the development of knowledge PEEXC aged 20 to 35 years on a better integration to reduce risk behaviours favouring the transmission of HIV/AIDS educators.

A general awareness of the issue of this strategy through media coverage.

Conclusion This training helped PEEXC on developing knowledge PEEXC as a strategy to reduce risk behaviours favouring the transmission of HIV/AIDS.

Next steps: It was anticipated identification of best practises that could be applied elsewhere in order to reduce risky behaviours favouring the transmission of HIV/AIDS among groups who have been affected by armed conflict in general and in particular ex-combatants BURUNDI the lead and support a psycho-social and medical PEEXC the tracks that have made a voluntary and living with HIV/AIDS to improve their quality of life.

\section{P4.110 SEXUAL RISK BEHAVIOR AND THE EFFICACY OF PSYCHO- EDUCATION IN IMPROVING ADHERENCE TO SECONDARY PREVENTION INFORMATION AMONG PEOPLE LIVING WITH HIV/AIDS IN IBADAN, NIGERIA}

doi:10.1136/sextrans-2013-051184.1007

O P Atibioke. Association for Reproductive and Family Health, Abuja, Nigeria

Background Findings have shown that adherence to secondary prevention information is low among people living with HIV and AIDS (PLWHAs) in Sub Saharan Africa including Nigeria. However, the effectiveness of Psycho-education has not been fully exploited. The Study therefore investigated the involvement of PLWHAs in sexual risk behaviour and the effectiveness of Psycho-education intervention on adherence to secondary prevention among PLWHAs in Ibadan, Nigeria.

Methods The study was conducted in two phases, first phase utilised ex-post facto design. Simple random sampling technique was used to select 548 (Males $=154$; Females $=394$ ) participants receiving anti-retroviral therapies in President's Emergency Plan for AIDS Relief University College Hospital, Ibadan after securing ethical approval, (Mean age of 39.5 years SD $=9.334$ years). Quantitative data were collected from participants through standardised questionnaire. Pre-test, post-test quasi experimental control group design was utilised for the second phase. Fifty participants were randomly selected from those who reported involvement in sexual risk behaviour in phase one and randomly assigned to Psycho-education group and control group.

Results Results revealed that; 70 representing 12.8\% have engaged in sexual risk behaviour by having sex with irregular partners without using condom. 66 representing $12 \%$ have had sex with more than one partner, 72 representing $13.1 \%$ have had sex with prostitute. Further analysis revealed that 185 representing $33.8 \%$ have had sexually transmitted infections. Finding from second stage which utilised Psycho-education intervention technique revealed that knowledge of secondary prevention has increased among the treatment group compare to control group $\{F(5,149)=11.943: p<0.001\}$ at follow up conducted eight weeks after intervention.

Conclusion From this study, it is evident that People living with HIV \& AIDS still engage in Sexual risk behaviour which negatively impact on treatment outcomes and Psycho-education intervention technique was found efficacious in addressing sexual risk behaviour among people living with HIV.

\section{P4.111 ENTERTAIN, ENGAGE, EDUCATE - HIV/AIDS IN RURAL INDIA}

doi:10.1136/sextrans-2013-051184.1008

M Annapoorni. Blossom Trust, Virudhunagar, India

Background The Paneer Poo HIV Positive Women's Network started life as a social support network helping PLHA women deal with the stigmas and hardships associated with the virus. HIV is vastly misunderstood in India by large swathes of the population. Rejection by friends and family, violence and refusal of medical care are common. PP were creating awareness and education programmes in School/Colleges and speaking at District Committee meetings.

The greatest and most significant challlenge in India's war against HIV/AIDS is the one against taboo. In rural communities, where life moves slowly, unchanging, taboos prove the strongest. A largely illiterate population exasperates the situation and forces a tailored approach to delivering effective messages. Important to rural Tamil Nadu are regular local theatrical and musical performances. It made sense to take advantage of this to deliver a message.

Method The EduClowns are a trained collective of people who travel to schools, colleges and villages. Wearing the mask and clothing of the clown the performers are able to step out of themselves, as a clown they are no longer restricted by the traditional boundaries that hold them to taboo and prevent them from dissecting stigma. When representing Paneer Poo the clowns would start with dance, song and comedy. There is then audience participation with games and question/answer. Short skits are then performed that highlight AIDS/HIV issues, provoking thought and discussion on the subject. Finally, a scene where taboos are defeated and community action has provoked positive change.

Results The EduClowns, on behalf of Paneer Poo, performed 11 times in 2012/13 with hundreds of people at each event. Nearly 200 people went forward to receive an HIV test. Paneer Poo also conducted 27 awareness meetings, reaching over 1600 people.

Conclusion A theatrical education based approach can be successful and suited to rural India.

\section{P4.112 SEXUAL HEALTH META-ANALYSIS}

doi:10.1136/sextrans-2013-051184.1009

J S Becasen, J Ford, M Hogben. Centers for Disease Control and Prevention, Atlanta, GA, United States

Background US population-level rates of sexual health indicators such as STI rates have stimulated interest in a public health approach to improving sexual health, focusing in six domains: knowledge, attitudes and norms, communication, healthcare use, sexual behaviour and adverse outcomes We conducted a systematic review of the intervention literature in these domains to assess the extent to which existing research supported sexual health principles: recognition of sexuality as intrinsic to individual health and relationships should have positive outcomes for all partners involved.

Methods Studies were drawn from Medline and PsycInfo databases (English language, adult populations, published between 1996-2011, country with developed public health infrastructure). 
Sufficient studies for meta-analytic review were in three domains: knowledge, attitudes, and sexual behaviours. To examine main intervention effects within each domain, study's intervention characteristics were extracted to compute the pooled Hedges' $g$ and $95 \%$ CIs using the random-effects model. Effect size heterogeneity was measured by $\mathrm{I}^{2}$.

Results From 9064 candidates, 21 studies across three domains were included in the meta-analysis. For knowledge, there was a large intervention effect on sexual health knowledge, Hedges' $g=1.32(0.51-2.14)$. The pooled effect size for both attitudes and sexual behaviour domains yielded small to medium intervention effects, Hedges' g $=0.58(0.34-0.81)$ and 0.25 (0.13-0.37), respectively. Heterogeneity for each domain was substantial (between $91 \%$ and $97 \%$ ). Removal of outliers decreased heterogeneity estimates for all domains ( $21 \%$ to $62 \%$ ), i.e., small. The final effects sizes for knowledge, attitudes and sexual behaviour were 0.25 $(0.03-0.48), 0.21(0.15-0.28)$ and $0.10(0.06-0.15)$, respectively.

Conclusions Our results indicate that existing intervention efforts focused on sexual health knowledge, attitudes and behaviour have small, but positive significant effects. Studies were not designed to encompass all the domains of sexual health, but when studies were examined by these domains the results were consistent across the studies.

\section{P4.113 STIGMA, DISCRIMINATION AND UNDUE PRESSURE FACED BY MSM'S FROM THE FAMILY, PEERS AND SOCIETY LEADING TO A DOUBLE STANDARD LIFE}

doi:10.1136/sextrans-2013-051184.1010

'Z Haq, 'R Akber, ${ }^{2}$ Oasim, ${ }^{2} \mathrm{R}$ Bushra, ${ }^{3} \mathrm{~K}$ Sheryar. ${ }^{1}$ parwaz male health society, karachi, Pakistan, ${ }^{2}$ Naz Male Health Alliance, Lahore, Pakistan, ${ }^{3}$ Naz Male Health Alliance, karachi, Pakistan

Background Parwaz Male Health Society is implementing GFATM's Regional Grant R-9 to empower MSM/TG communities in Pakistan to prevent HIV/AIDS, under the technical assistance provided by Naz Male Health Alliance, Pakistan. Participatory research methods is used to reach MSM and understand community needs to effectively design prevention-programmes in Karachi, where MSM's are engaged in high risk behaviours to an alarmingly high level which makes them vulnerable to HIV/AIDS.

Methods A case study approach was used to analyse data involving the MSM community members; Malishias, truck/cab/drivers, migrant, labour, and self identified gay people etc. visiting the Drop in Center. 12 cases were studied and Data was collected through In-depth interviews, participant's observation and data verification, done through the field workers, Community counsellor and the Doctor. Ethical standards mentioned in NMHA's Institutional manual.

Results Ranging between the age group 16-50 years, MSM's have been subjected to labelizing, stigmatisation, discrimination since childhood within home and the external world, whether educated or uneducated, financially stable or not, low self esteem, lack of understanding and knowledge on self identity and human rights, facing violence/bullying from around, forced decisions about marriage, career and religious practises, altered mental and physical development and a damaged personality, hampering their productivity and efficiency to contribute to society in a healthy way.

Conclusion An urgent need for an all age group focused programming covering Psycho social and sexual health, strategies to cope with bullying and pressure inflicted including counselling and self help group therapy, acceptance of self identity, socio-economic empowerment, education and awareness along HIV and Sexually Transmitted Infections prevention. Further qualitative and quantitative evidence is required to effectively design programmes.

\section{P4.114 SEXUAL BEHAVIOR AND PRACTICE AMONG TRANSGENDERS IN WEST BENGAL, INDIA}

doi:10.1136/sextrans-2013-051184.1011

M Kundu, N Panda, S Chowdhury, S Das konar, R Basu, D Das, R Sonkar, A RoyChoudhury. Child In Need Institute, Kolkata, India

HIV Epidemic in India is not generalised but is a concentrated epidemic. The Prevalence of HIV among Transgender is 8.82, thus there is the necessity for specific programmes. Hence, a study among the transgender conducted to know the sexual behaviour \& practise among them.

A structured questionnaire had been developed followed by training of the interviewer. The respond Driven Sampling method was used. The study had been conducted in collaboration with Community Based Organization working with Transgender in West Bengal.

According to this study the $30 \% \& 42 \%$ respondents have secondary and graduate level of education whereas $28 \%$ are post graduate. $25 \%$ populations below 18 years have more than 10 sexual partner and 18 years above have 7 partners on an average in a month. $43 \%$ respondents have exposure of sexual intercourse before the age of 13 \& rests $57 \%$ between the ages 14 to $18.12 \%$ are married with female but all of them preferred \& practise anal sex and have multiple male sexual partners. $81 \%$ contact with their partners through mobile phone or use e-communication which hampers the so called Outreach concept. $88 \%$ do not know about the sign \& symptoms of STI but $67 \%$ of them being affected with it. $83 \%$ are inconsistent condom user and they have complained of condom rupture during sex \& unavailability of lubricant. $80 \%$ populations have self risk perception to get HIV.

Indian National HIV Programme Design need to cater specific need based tailor made Transgender Programme. Need convergence of Adolescent \& HIV Programme for Transgender. Incorporate Social Media, phone in new outreach strategy for more reaching out. National HIV prevention Programme needs specific male STI Guideline. The Self Risk perception among this community is very high so immediate new programme strategy will help the Transgender Community to prevent HIV.

\section{P4.115 THE FORGOTTEN STI: A SURVEY OF KNOWLEDGE ABOUT TRICHOMONIASIS}

doi:10.1136/sextrans-2013-051184.1012

'D Arrindell, 'L Barclay, ${ }^{2} \mathrm{~J}$ Boxt. 'American Sexual Health Association, Durham, NC, United States, ${ }^{2}$ Glover Park Group, Washington, DC, United States

Background Trichomoniasis is the most common curable STI in the US. According to the Centers for Disease Control and Prevention, an estimated 7.4 million new cases occur each year. Trich is a largely hidden STI - out of the public eye, and absent from serious discussions about STI prevention. Increasing awareness requires improved understanding of what women know to develop messages to encourage testing.

Methods A survey was conducted on behalf of American Sexual Health Association via an online panel by Research Now, an independent research company. Interviews were conducted between January $28^{\text {th }}$ - February $2^{\text {nd }}, 2013$ among a nationally representative sample of 1,000 female respondents between the ages of 18 and 50 .

Results Women surveyed perceive trich as the least common STI; only one in five $(22 \%)$ women are familiar with it. Sixty-five percent would not seek medical attention if they experienced unusual symptoms, instead waiting to see if the symptoms go away or treating themselves with over-the-counter medicine. Those most likely to self-treat include Hispanic women (33\%), those with a high school or less education (33\%), and Southerners (32\%). Among 